CrossMark \& click for updates

Cite this: Mater. Chem. Front. 2017, 1, 24

\title{
Two-dimensional transition metal dichalcogenide nanomaterials for biosensing applications
}

\author{
Yanling Hu, $\dagger^{\mathrm{ab}}$ Ying Huang, $\dagger^{\mathrm{b}}$ Chaoliang Tan, ${ }^{\mathrm{b}}$ Xiao Zhang, ${ }^{\mathrm{b}}$ Qipeng Lu, ${ }^{\mathrm{b}}$ \\ Melinda Sindoro, ${ }^{\mathrm{b}}$ Xiao Huang, ${ }^{\mathrm{C}}$ Wei Huang, ${ }^{\mathrm{ac}}$ Lianhui Wang*a and Hua Zhang ${ }^{\star b}$
}

\begin{abstract}
Biosensors are powerful tools used to monitor biological and biochemical processes, ranging from clinical diagnosis to disease therapy. The huge demands for bioassays greatly promote the development of new nanomaterials as sensing platforms. Two-dimensional (2D) nanomaterials with superior properties, such as large surface areas and excellent conductivities, are excellent candidates for biosensor applications. Among them, single- or few-layered transition metal dichalcogenide (TMD) nanomaterials represent an emerging class of 2D nanomaterials with unique physical, chemical, and electronic properties. In this mini-review, we summarize the recent progress in 2D TMD nanomaterial-based biosensors for the sensitive detection of various kinds of targets, including nucleic acid, proteins, and small biomolecules, based on different sensors like optical sensors and electrochemical sensors, and bioelectronic sensors. Finally, the challenges and opportunities in this promising field are also proposed.
\end{abstract}

Received 31st August 2016,
Accepted 26th October 2016

DOI: $10.1039 / \mathrm{c} 6 q m 00195 \mathrm{e}$

rsc.li/frontiers-materials

\footnotetext{
${ }^{a}$ Key Laboratory for Organic Electronics and Information Displays (KLOEID) and Institute of Advanced Materials (IAM), National Jiangsu Synergetic Innovation Center for Advanced Materials (SICAM), Nanjing University of Posts and Telecommunications, 9 Wenyuan Road, Nanjing 210023, China.

E-mail: iamlhwang@njupt.edu.cn

${ }^{b}$ Center for Programmable Materials, School of Materials Science and Engineering, Nanyang Technological University, 50 Nanyang Avenue, Singapore 639798, Singapore.E-mail: hzhang@ntu.edu.sg

${ }^{c}$ Key Laboratory of Flexible Electronics (KLOFE) \& Institute of Advanced Materials (IAM), Jiangsu National Synergistic Innovation Center for Advanced Materials (SICAM), Nanjing Tech University (NanjingTech), 30 South Puzhu Road, Nanjing 211816, China

$\dagger$ These authors contributed equally to this work.
}

\section{Introduction}

With the increasing demand for disease diagnosis and therapies, biosensors have become powerful tools for the detection of biological analytes, such as nucleic acid, proteins, and small biomolecules. Generally, analytes extracted from biological systems are at a low concentration level, particularly for biomarkers of specific diseases..$^{1-3}$ Hence, over the past few decades, great efforts have been devoted to the design and development of ultrasensitive bioassays. Besides the development of advanced instruments and detection strategies for signal amplification,

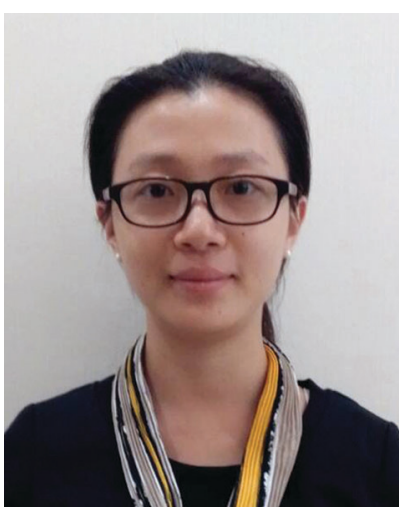

Yanling Hu
Yanling Hu received her BS degree in Applied Chemistry from Nanjing Normal University in 2011. After that, she moved to Nanjing University of Posts and Telecommunications where she is pursuing her PhD degree under the supervision of Professor Lianhui Wang. During 2015 to 2016, she studied and worked as an exchange student in Professor Hua Zhang's group in the School of Materials Science and Engineering, Nanyang Technological University,

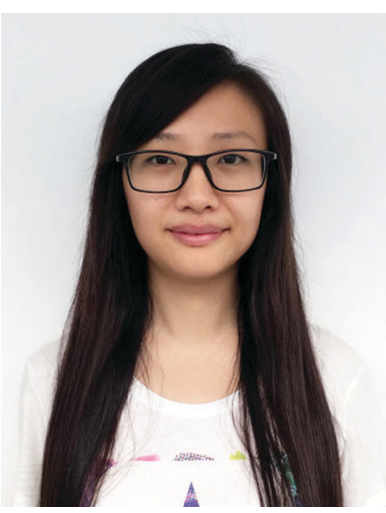

Ying Huang
Ying Huang received her $B E$ degree in Applied Chemistry from Hubei Normal University in 2009. After she got her ME degree from Sichuan University, she moved in 2014 to School of Materials Science and Engineering, Nanyang Technological University in Singapore where she is currently pursuing her PhD degree under the supervision of Professor Hua Zhang. Her research interests focus on the synthesis of twodimensional nanomaterials and their application in biosensors.

Singapore. Her research interests focus on the optical and electrochemical biosensors based on noble metallic nanomaterials and two-dimensional nanomaterials. 
the utilization of suitable materials in sensing applications is another important way to enhance the detection signal. ${ }^{4}$ It has been demonstrated that the performance of biosensors shows a close association with the intrinsic characteristics, e.g. structures, morphologies, compositions, and physicochemical properties, of the used nanomaterials. ${ }^{5,6}$ For example, nanomaterials with a large surface area, good conductivity, and excellent biological compatibility can be used as signal amplification elements in electrochemical sensors. ${ }^{7}$ Therefore, the exploration of new advanced nanomaterials is key to develop biosensors with a high sensitivity and low detection limit.

Two-dimensional (2D) nanomaterials have attracted broad interest due to their unconventional properties, especially after the 2010 Nobel Prize in physics was awarded for "groundbreaking experiments regarding graphene". ${ }^{8-14}$ Since then, a number of graphene-based biosensors have been reported. ${ }^{15-19}$ Inspired by graphene, other graphene-like 2D nanomaterials with singleand few-layer thickness came to light and have gained increasing attention in recent years, especially transition metal dichalcogenides (TMDs) which include $\mathrm{MoS}_{2}, \mathrm{WS}_{2}, \mathrm{TaS}_{2}, \mathrm{TiS}_{2}, \mathrm{WSe}_{2}, \mathrm{MoSe}_{2}$, etc. $^{20-29}$ To date, a wide variety of synthetic methods have been developed to prepare single- and few-layered 2D TMD nanosheets, namely, mechanical cleavage, chemical vapor deposition (CVD), wet-chemical synthesis, chemical or electrochemical Li-intercalation and exfoliation, as well as liquid phase

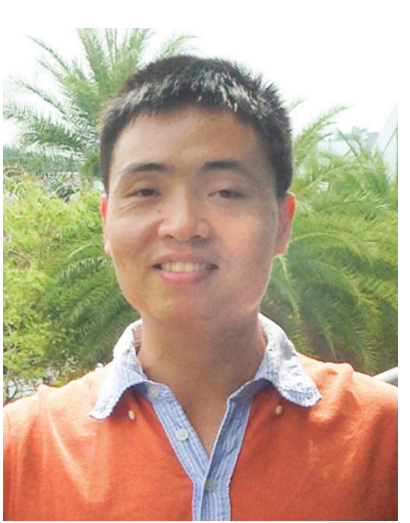

Chaoliang Tan
Chaoliang Tan received his $B E$ and $M E$ degrees in Applied Chemistry from Hunan University of Science and Technology (China) in 2009 and South China Normal University (China) in 2012, respectively. He then moved to the School of Materials Science and Engineering of Nanyang Technological University (Singapore) in 2012 where he completed his PhD under the supervision of Professor Hua Zhang in 2016. Currently, he is a Research Fellow in Professor Hua Zhang's group. His research interests focus on the synthesis, characterization and applications of ultrathin twodimensional nanomaterials (e.g. transition metal dichalcogenides) and their functional heterostructures/composites.

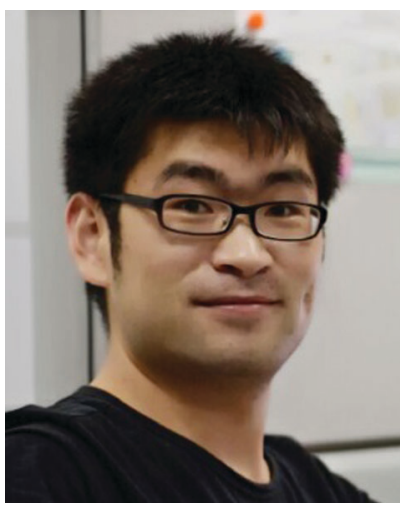

Xiao Zhang
Xiao Zhang received his $B E$ and $M E$ degrees at Harbin Engineering University in 2010 and 2013, respectively. Then, he moved to the Interdisciplinary Graduate School of Nanyang Technological University in Singapore as a PhD student under the supervision of Professor Hua Zhang (2013). His research interest is in the synthesis and applications of novel twodimensional nanomaterials.

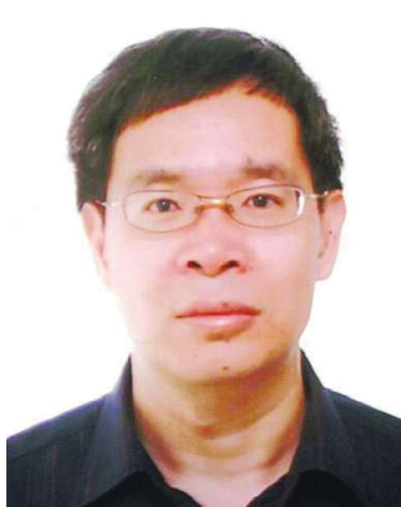

Lianhui Wang
Lianhui Wang obtained his MS degree at Fujian Normal University in 1993, and received his $P h D$ degree from Zhejiang University in 1998. Then he moved to National University of Singapore as a Postdoctoral Fellow. After working as a Research Fellow and assistant professor at the Institute of Molecular and Cell Biology, he joined Fudan University as a professor in 2005. In 2011, he moved to Nanjing University of Posts and Telecommunications as a professor. His research interests focus on nanobiology, chemical biology, bioelectronics, biosensors, etc.

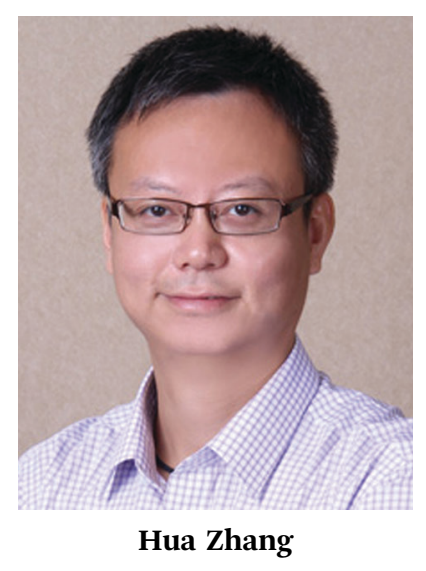

Hua Zhang obtained his BS and MS degrees at Nanjing University in 1992 and 1995, respectively, and completed his PhD with Prof. Zhongfan Liu at Peking University in 1998. As a Postdoctoral Fellow, he joined Prof. Frans C. De Schryver's group at Katholieke Universiteit Leuven (Belgium) in 1999, and then moved to Prof. Chad A. Mirkin's group at Northwestern University in 2001. After working at NanoInk Inc. (USA) and the Institute of Bioengineering and Nanotechnology (Singapore), he joined Nanyang Technological University in July 2006. His current research interests focus on the synthesis of ultrathin two-dimensional nanomaterials (e.g. metal nanosheets, graphene, metal dichalcogenides, metal-organic frameworks, etc.) and their hybrid composites for various applications; controlled synthesis, characterization and application of novel metallic and semiconducting nanomaterials, complex heterostructures, etc. 
exfoliation in different solvents. ${ }^{30-36}$ Due to their ultrathin thickness and 2D structure, these TMD nanosheets present unique physical, chemical, optical, and electronic properties compared with their bulk counterparts..$^{20-22,37,38}$ In addition, 2D TMD nanosheets can directly interact with biomolecules, resulting in their surface modification/decoration. This could greatly extend their range of biosensing. Taking $\mathrm{MoS}_{2}$ as an example, structural defects, such as point defects and edges, play important roles in sensing applications. ${ }^{39,40}$ On account of these attractive properties as well as large specific surface areas, 2D TMD nanosheets hold great potential in biosensing applications. ${ }^{41,42}$

This mini-review aims to provide an overview of the recent advances on 2D TMD nanosheets for biosensing applications. First, we describe the structure and properties of 2D TMD nanosheets. Then, we present the recent development of TMD nanosheet-based biosensors for the detection of different biological analytes including nucleic acid, proteins, and small molecules through various sensing approaches like optical methods, electrochemical methods, and electronic methods. Finally, based on the current studies, the opinions on the challenges and opportunities in this hot field are proposed.

\section{Structure and properties of 2D TMD nanomaterials}

TMDs are $\mathrm{MX}_{2}$-type compounds with layered structures, which are made by strong in-plane covalent bonding along with weak interactions between the layers, especially for group 4-7 TMDs (Fig. 1a), while some of the group 8-10 TMDs are commonly presented in non-layered structures. ${ }^{20}$ In each $\mathrm{MX}_{2}$ monolayer, a layer of transition metal atom (M) is sandwiched between two chalcogen atom layers ( $\mathrm{X}=\mathrm{S}$, Se, or Te), giving 6-7 $\AA$ of thickness for each monolayer. ${ }^{43-45}$ The properties of TMD materials change along with a decrease in the number of layers. For example, the bandgap of bulk $\mathrm{MoS}_{2}$ is about $1.3 \mathrm{eV}$ while that of single-layered $\mathrm{MoS}_{2}$ is $1.8-1.9 \mathrm{eV},{ }^{46}$ showing an indirect-to-direct bandgap transition as the thickness decreased to a single layer. In addition, the surface areas of TMD materials greatly increase after being exfoliated into single or few layers.

Of particular interest is that TMD materials exhibit various polymorphs, commonly including $1 \mathrm{~T}, 2 \mathrm{H}$, and $3 \mathrm{R}$, which stand for trigonal, hexagonal, and rhombohedral crystal phases, respectively. ${ }^{47,48}$ However, when exfoliated into a single layer, TMD materials exhibit two polymorphs: $1 \mathrm{~T}$ and $2 \mathrm{H}$ (Fig. $1 \mathrm{~b}$ and $\mathrm{c}$ ). It is worth noting that the phase transformation between these phases can be realized by various strategies. Taking $\mathrm{MoS}_{2}$ as an example, the $3 \mathrm{R}$ phase can be transformed into $2 \mathrm{H}$ phase upon heating. ${ }^{47}$ Moreover, the crystal structure of $\mathrm{MoS}_{2}$ can be partly engineered from $2 \mathrm{H}$ to $1 \mathrm{~T}$ by intercalating alkaline metals $(\mathrm{Li}, \mathrm{K}$, or $\mathrm{Na}$ ) in the exfoliation process. ${ }^{4-52}$ Note that the phase transformation from $2 \mathrm{H}$ to $1 \mathrm{~T}$ is accompanied by a change in the density of states, resulting in the evolution of $\mathrm{MoS}_{2}$ from a semiconductor to a metal. ${ }^{53}$

These aforementioned unique properties make the singlelayered TMD nanosheets good candidates for the fabrication of biosensors. For example, the increased bandgap of $\mathrm{MoS}_{2}$ nanosheets makes it a better choice for electronic devices. ${ }^{54}$ The phase transformation of $\mathrm{MoS}_{2}$ from a semiconductor to a metal can enhance its electrical conductivity which benefits the electrochemical properties. ${ }^{55,56}$ Moreover, the large surface area of single-layered TMD nanosheets enables high physical adsorption of biomolecules onto their surface. Simultaneously, 2D TMD nanosheets present an efficient fluorescence quenching ability for fluorophores, rendering them promising platforms for the construction of fluorescence-based biosensors. ${ }^{57,58}$ Our group first reported the physisorption of single-layered $\mathrm{MoS}_{2}$ nanosheets towards single-stranded DNA (ssDNA) and studied its efficient quenching ability. ${ }^{59}$ As the physisorption of aromatic and conjugated compounds on the $\mathrm{MoS}_{2}$ surface has been proposed, the ssDNA adsorption is believed to be a result of the van der Walls force between nucleobases and the basal plane of the $\mathrm{MoS}_{2}$ nanosheet. ${ }^{60}$ The principle also holds that the lower adsorption of double-stranded DNA (dsDNA), with nucleobases buried between their helical phosphate backbones, occurs on $\mathrm{MoS}_{2}$ nanosheets. Besides DNA hybridization, the adsorption of the DNA probe can also be weakened by 3D structural switching resulting from specific aptamer-target recognition.

\section{2D TMD nanomaterial-based biosensors}

\subsection{D TMD nanomaterials used for optical biosensors}

Optical biosensors are attracting huge attention for disease diagnosis and clinical evaluation due to their simple, fast, and direct read out properties. ${ }^{61-64}$ Fluorescence sensing and colorimetric methods are two typical sensing techniques for optical biosensors. ${ }^{15,65,66}$ Since TMD nanosheets could act as fluorescence quenchers and peroxide mimics, a series of optical biosensors based on TMD nanosheets have been developed.

3.1.1 Detection of nucleic acids. Single- or few-layered TMD nanosheets have pretty good fluorescence quenching abilities. Our group first demonstrated that the $\mathrm{MoS}_{2}$ nanosheet has an efficient quenching ability towards dye-labeled ssDNA. ${ }^{59}$ Due to the different affinities towards SsDNA and dsDNA, the fluorescence of ssDNA can be almost entirely quenched by the $\mathrm{MoS}_{2}$ nanosheet. While in the presence of target DNA, dsDNA was formed and released from the surface of the $\mathrm{MoS}_{2}$ nanosheets, resulting in the fluorescence recovery. The designed DNA sensor showed a detection limit of $500 \mathrm{pM}$ with a linear range of 0-15 nM. Moreover, this concept has been extended to other TMD nanosheets for DNA detection, including $\mathrm{WS}_{2}, \mathrm{TaS}_{2}$ and $\mathrm{TiS}_{2}$, and ternary metal chalcogenide nanosheets (e.g. $\left.\mathrm{Ta}_{2} \mathrm{NiS}_{5}\right){ }^{67-69}$ Recently, Huang and co-workers combined this strategy with a microfluidic technique and developed a microfluidic chip for DNA detection. ${ }^{70}$ This method can effectively reduce the sample volume and realize rapid detection of DNA, achieving a detection limit as low as $\sim$ fmol. If the probe DNA is replaced by the dye-labeled PNA, it can hybridize with the complementary DNA to form a PNA-DNA duplex. Based on this idea, Wang et al. used the $\mathrm{WS}_{2}$ nanosheet to fabricate biosensors for DNA detection based on the different affinities 


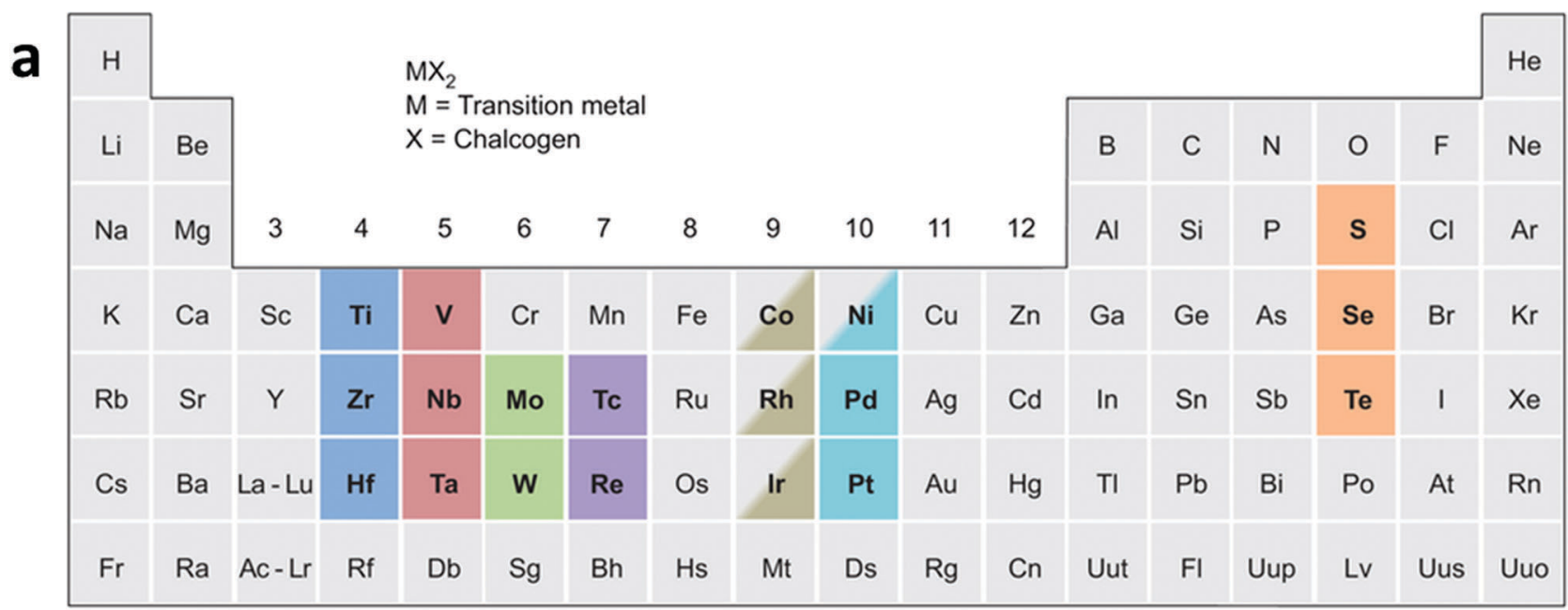

b

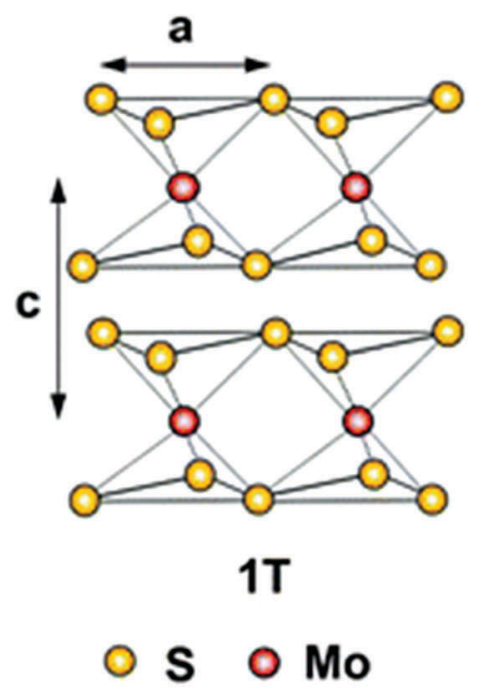

C

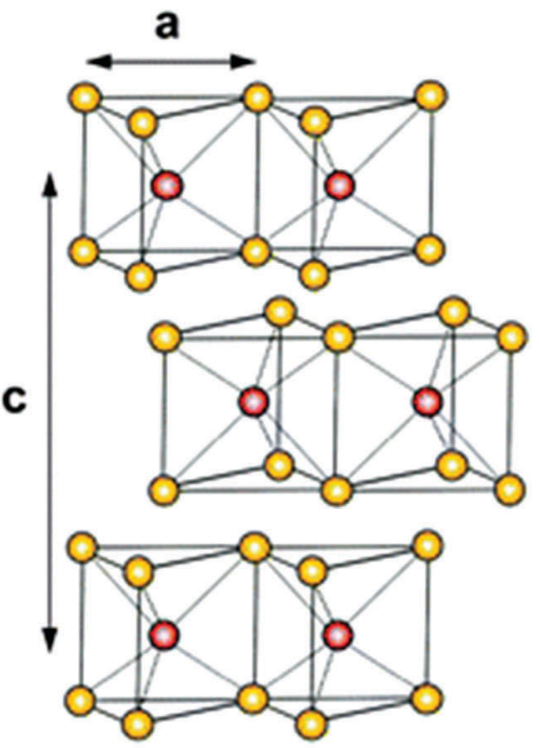

$2 \mathrm{H}$

Fig. 1 (a) Various kinds of TMD nanomaterials, reproduced with permission from ref. 20. Copyright 2013 Nature Publishing Group. Schematic illustration of (b) the $1 \mathrm{~T}$-type and (c) the $2 \mathrm{H}$-type structure of $\mathrm{MoS}_{2}$. Reproduced with permission from ref. 8. Copyright 2013 Royal Society of Chemistry.

between the $\mathrm{WS}_{2}$ nanosheet and PNA or the PNA-DNA duplex, resulting in a limit of detection of $500 \mathrm{pM}^{71}$

Fluorescent biosensors for microRNA (miRNA) detection are very important, since miRNA plays a significant role in physiological and pathological processes and can be used as a biomarker for disease diagnosis. Great efforts have been devoted to the development of biosensors by using TMD nanosheets for miRNA detection. The $\mathrm{WS}_{2}$ nanosheet was reported to show weaker affinities towards short ssDNA compared to long ssDNA. ${ }^{72}$ This property has been applied to design a fluorescent sensor for miRNA detection by Jiang et al. $^{72}$ A dye-labeled ssDNA was used as the probe whose fluorescence can then be quenched by the $\mathrm{WS}_{2}$ nanosheet. In contrast, in the presence of target miRNA and duplex-specific nuclease (DSN), the formed DNA-RNA heteroduplex could be cleaved to release target miRNA to hybridize with other probe ssDNA, leading to cyclic reaction and signal amplification. This method further pushed the miRNA detection limit down to $300 \mathrm{fM}$. Obviously, the fluorophore could be replaced by other kinds of molecule beacons. Zhao et al. proposed a chemiluminescence (CL) resonance energy transfer (CRET) sensing platform for miRNA detection. ${ }^{26}$ In this case, part of the probe DNA can form a G-quadruplex-hemin- $\mathrm{H}_{2} \mathrm{O}_{2}$-luminol structure and give strong $\mathrm{CL}$ which can be quenched by the $\mathrm{WS}_{2}$ nanosheet due to the interaction between ssDNA and the G-quadruplex-hemin DNAzyme structure. In the presence of target miRNA, the formed DNA-RNA heteroduplex showed a weak affinity with the $\mathrm{WS}_{2}$ nanosheet and desorbed from the $\mathrm{WS}_{2}$ nanosheet surface, leading to restoration of the CL signal. The CL intensity and the concentration of miRNA showed a linear relationship in the range of $0.5-10 \mathrm{nM}$, yielding a detection limit of $\sim 180 \mathrm{pM}$. 
3.1.2 Detection of proteins. TMD nanosheets can also be used for protein detection using the fluorescence method. Nucleic-acid aptamers are usually utilized for the specific recognition of proteins and other biomolecules due to their advantages of chemical stability and in vitro synthesis. ${ }^{73}$ Recently, Ge et al. reported that the dye-labeled ssDNA aptamer probe can be self-assembled on the $\mathrm{MoS}_{2}$ nanosheet surface to induce the fluorescence resonance energy transfer from the dye to $\mathrm{MoS}_{2}$, resulting in the quenching of the fluorescence intensity. ${ }^{74}$ In the presence of the detection target, taking human $\alpha$-thrombin as an example, the aptamer could specifically bind with the target to form a rigid conformation, resulting in the release of the DNA aptamer probe from the $\mathrm{MoS}_{2}$ nanosheet surface and partial restoration of the fluorescence (Fig. 2a). ${ }^{74}$ This method achieved a detection limit of $300 \mathrm{pM}$, which is better than that of a graphenebased $\alpha$-thrombin biosensor. ${ }^{75}$ Besides human $\alpha$-thrombin, other proteins such as carcinoembryonic antigen (CEA), ${ }^{76}$ prostate specific antigen (PSA), ${ }^{77}$ and cytochrome $\mathrm{c}^{78}$ can also be analyzed through this method.

Besides protein detection using nucleic-acid aptamers, Xiang and co-workers have converted a protein assay into DNA detection by combining the terminal protection of small-molecule-linked DNA with exonuclease III (Exo III)-aided DNA recycling amplification. ${ }^{79}$ As shown in Fig. $2 \mathrm{~b}$, in the sensing process, a dye-labeled probe 2 could hybridize with a biotin-modified probe 1 and tether to the $3^{\prime}$-end of the antisense strand. Probe 1 was digested by exonuclease I (Exo I) in the absence of SA. Probe 2 was adsorbed onto the $\mathrm{MoS}_{2}$ nanosheet surface, resulting in a low fluorescence signal. While in the presence of streptavidin (SA), the SA and biotin could specifically bind together and protect probe 1 from Exo I-assisted digestion. After hybridization with probe 2, the DNA duplex formed and probe 2 could be degraded by Exo III, resulting in a cyclic amplification and the release of more probe 2 from $\mathrm{MoS}_{2}$. This strategy achieved highly sensitive SA detection with a detection limit of $0.67 \mathrm{ng} \mathrm{mL}^{-1}$.

2D TMD nanosheet-based optical biosensors have also been applied to detect T4 polynucleotide kinase (PNK), which can phosphorylate DNA and plays a significant role in many cellular events. For example, Ge et al. developed a $\mathrm{WS}_{2}$ nanosheet-based optical sensing platform to analyze nucleotide kinase activity. ${ }^{80}$ In the presence of T4 PNK, dsDNA could be cleaved by $\lambda$ exonuclease, leaving a FAM-labeled ssDNA. In this case, the fluorescence of the FAM-labeled ssDNA could be quenched by the $\mathrm{WS}_{2}$ nanosheet. As shown in Fig. 2c, in the absence of T4 PNK, the $\lambda$ exonuclease showed low activity towards nonphosphorylated dsDNA. The remaining dsDNA showed a strong fluorescence signal because of the weak affinity towards the $\mathrm{WS}_{2}$ nanosheet. This strategy offered a detection limit of $0.01 \mathrm{U} \mathrm{mL}^{-1}$. Recently, Liu et al. used hairpin DNA coupled with DNA polymerase and deoxyribonucleoside triphosphates (dNTPs) for T4 PNK assay, achieving a detection limit of $0.05 \mathrm{U} \mathrm{mL}^{-1}$. $^{81}$

3.1.3 Detection of small molecules. 2D TMD nanosheets can be designed for the detection of small molecules. Considering that DNA aptamers can be tuned according to different targets, similar fluorescent methods based on TMD nanosheets can be used to detect small biomolecules, such as adenosine and adenosine triphosphate (ATP). ${ }^{59,74}$

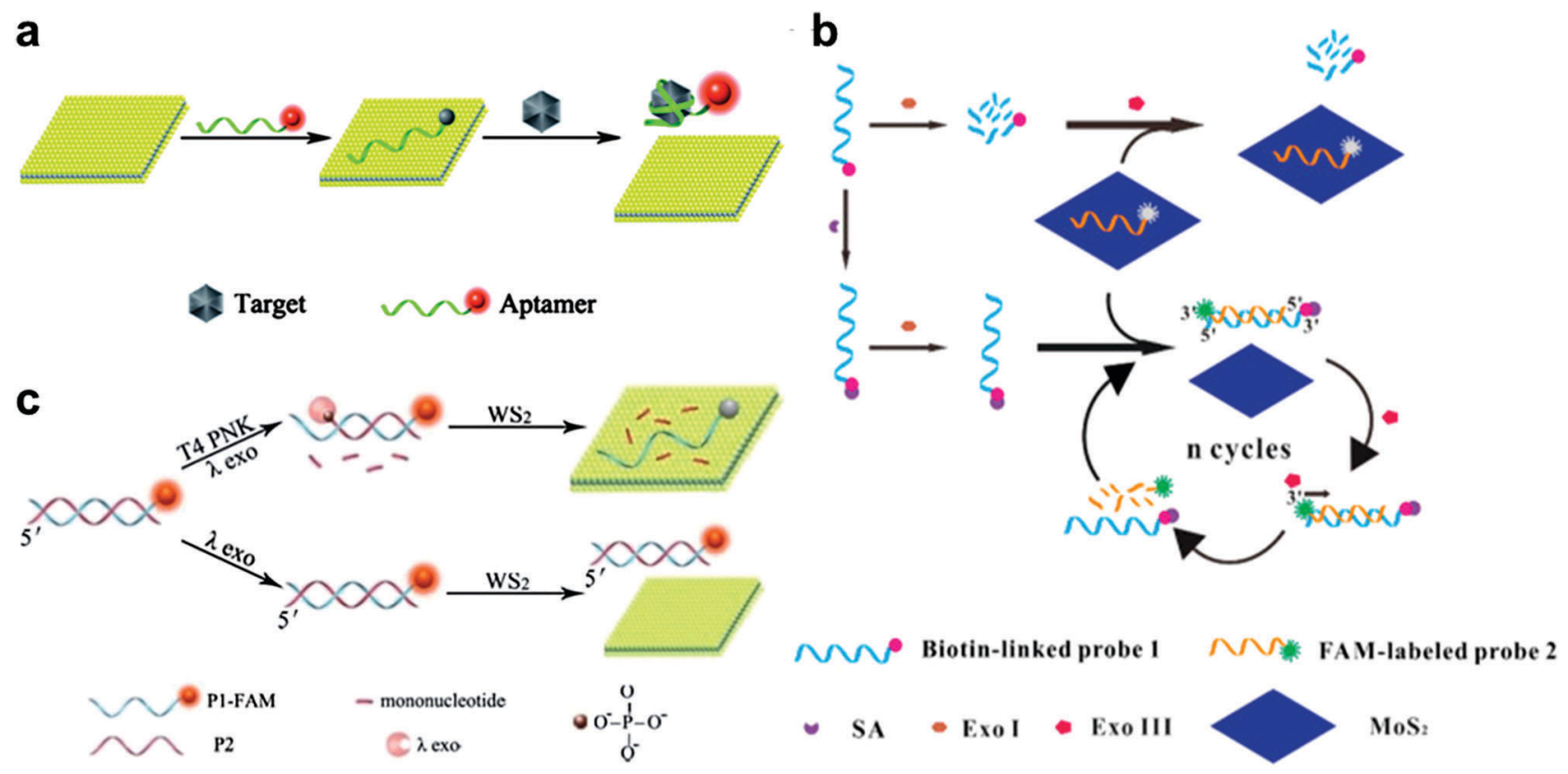

Fig. 2 (a) Schematic illustration of the $\mathrm{MoS}_{2}$ nanosheet used as an effective sensing biosensor. Reproduced with permission from ref. 74 . Copyright 2014 Royal Society of Chemistry. (b) Schematic illustration of the mechanism of a MoS 2 -based biosensor for the detection of SA via terminal protection of small-molecule-linked DNA and Exo III-aided DNA recycling amplification. Reproduced with permission from ref. 79. Copyright 2015 Elsevier. (c) Schematic illustration of the $\mathrm{WS}_{2}$ nanosheet-based platform for T4 PNK activity and inhibition analysis. Reproduced with permission from ref. 80. Copyright 2014 Royal Society of Chemistry. 
Besides approaches based on the fluorescence quenching abilities of TMD nanosheets, the colorimetric method has also been used for the detection of small biomolecules due to its advantages, such as simplicity, rapidity, and visibility. ${ }^{82}$ The ability of $\mathrm{MoS}_{2}$ and $\mathrm{WS}_{2}$ nanosheets to serve as peroxidase mimics has been widely reported, and thus they can be used for the detection of $\mathrm{H}_{2} \mathrm{O}_{2}$ and glucose ${ }^{83,84}$ A color change occurred in the presence of $\mathrm{H}_{2} \mathrm{O}_{2}$ when the $\mathrm{MoS}_{2}$ nanosheet catalyzed the reaction of the peroxidase substance such as $3,3^{\prime}, 5,5^{\prime}$-tetramethylbenzidine (TMB). The $\mathrm{MoS}_{2}$ nanosheet-TMB- $\mathrm{H}_{2} \mathrm{O}_{2}$ system provided a detection limit of $1.5 \mu \mathrm{M}$ with a linear range from 5 to $100 \mu \mathrm{M}$ for $\mathrm{H}_{2} \mathrm{O}_{2}$ detection. This method could be used for glucose detection because hydrogen peroxide is the main product of the GOx-catalyzed reaction. The linear range was from 5 to $150 \mu \mathrm{M}$ with a detection limit of $1.2 \mu \mathrm{M}$. Furthermore, a portable test kit was developed to evaluate the glucose level in human serum samples, as a proof of concept, due to its visibility and small sample requirement.

\subsection{D TMD nanomaterials used for electrochemical biosensors}

Electrochemical biosensors have been widely used as effective assay methods for clinical diagnosis, environment monitoring, and food safety in the past few decades due to their simplicity, low cost, high sensitivity, and selectivity. Recently, 2D TMD nanomaterials have attracted great attention in the construction of electrochemical biosensors for the detection of various analytes. The ability of TMD nanosheets to prompt the electron transfer rate has been demonstrated due to the exposed active sites on their edges. ${ }^{85}$ Moreover, TMD nanosheets with an atomic layer structure and a large surface area can act as substrates to support other nanomaterials, including noble metals, transition metals, carbon materials and conductive polymers, further improving their electrochemical biosensing performances. Therefore, the decoration of noble metal nanoparticles (NPs) on the surface of TMD nanosheets has been considered as an efficient way to amplify their electrochemical signals. The Au NP is the most popular one because of its excellent electrical properties and biocompatibility. ${ }^{11,86,87}$ Furthermore, the surface of Au NP-decorated TMD nanosheets can be functionalized by various molecules. Besides the noble metal NPs, the carbon materials, conductive polymers and transition metals have also been used to modify TMD nanosheets to increase the electrical conductivity and surface area, thus improving the electrochemical performance. $^{88-91}$

3.2.1 Detection of nucleic acids. 2D TMD nanomaterials have been explored for the electrochemical detection of nucleic acids in recent years. There are three main advantages of using TMD nanosheets in electrochemical nucleic acid biosensors. First, TMD nanosheets show different affinities for ssDNA and dsDNA. Second, they can be modified by other molecules due to internal defects and edges. Third, integration of TMD nanosheets with other nanomaterials makes them promising signal amplification platforms for the detection of nucleic acids. For example, Loo et al. proposed a sensing platform for DNA detection using the $\mathrm{MoS}_{2}$ nanoflake as an inherently electroactive label based on the different affinities of $\mathrm{MoS}_{2}$ towards ssDNA and dsDNA. This biosensor presented a linear range towards the complementary DNA from 0.03 to $300 \mathrm{~nm} .{ }^{92}$ In addition, Wang et al. developed a $\mathrm{MoS}_{2}$-thionin composite modified electrode for the detection of dsDNA through the intercalation and electrostatic interaction of thionin with DNA. The peak current decreased along with the increase of the dsDNA concentration. A linear response to dsDNA from 0.09 to $1.9 \mathrm{ng} \mathrm{mL^{-1 }}$ was achieved even in the presence of a relatively high concentration of protein. ${ }^{93}$ In order to clearly illustrate 2D TMD nanomaterials for the detection of DNA, we summarize the detection performances using different TMD nanosheet-based electrodes in Table 1.

3.2.2 Detection of proteins. Besides nucleic acids, TMD nanosheet-based electrochemical biosensors can also be used for the detection of proteins by immobilizing different antibodies to capture the corresponding antigens on TMD nanosheetbased electrodes. The high selectivity and sensitivity can be achieved based on the specific interaction between antibodies and antigens. The sensitivity can be further improved by integration of TMD nanosheets with other nanomaterials, such as metal NPs and graphene. For example, Wang et al. proposed a sandwich-type immunosensor based on the $\mathrm{MoS}_{2}$-Au composite for the detection of CEA. ${ }^{100}$ The $\mathrm{MoS}_{2}$-Au composite was used to immobilize the CEA primary antibody (Ab1) and Ag NPs were used to support the CEA secondary antibody (Ab2) and glucose oxidase (GOx). In the presence of glucose, $\mathrm{H}_{2} \mathrm{O}_{2}$ was produced and then catalyzed by the $\mathrm{MoS}_{2}-\mathrm{Au}$ composite. The reduction peak of $\mathrm{H}_{2} \mathrm{O}_{2}$ was measured. This immunosensor exhibited a linear range from 1 to $50 \mathrm{ng} \mathrm{mL}^{-1}$ and a detection limit of $0.27 \mathrm{pg} \mathrm{mL^{-1 }}$ was achieved. As another example, a label-free electrochemical

Table 1 Comparison of DNA sensing performances using different TMD nanosheet-based electrodes

\begin{tabular}{|c|c|c|c|}
\hline Materials & Linear range & Detection limit & Ref. \\
\hline $\mathrm{MoS}_{2}$ & $0.03-300 \mathrm{nM}$ & - & 92 \\
\hline $\mathrm{MoS}_{2}$ & $10^{-16}-10^{-10} \mathrm{M}$ & $1.9 \times 10^{-17} \mathrm{M}$ & 94 \\
\hline $\mathrm{MoS}_{2}$-thionin & $0.09-1.9 \mathrm{ng} \mathrm{mL}^{-1}$ & - & 93 \\
\hline $\mathrm{MoS}_{2}$-multi-walled carbon nanotube-Au nanoparticle-glucose oxidase & $10-10^{7} \mathrm{fM}$ & $0.79 \mathrm{fM}$ & 95 \\
\hline $\mathrm{MoS}_{2}-\mathrm{ZnO}$ & $10^{-15}-10^{-6} \mathrm{M}$ & $6.6 \times 10^{-16} \mathrm{M}$ & 96 \\
\hline $\mathrm{MoS}_{2}$-polyaniline & $10^{-15}-10^{-6} \mathrm{M}$ & $2 \times 10^{-16} \mathrm{M}$ & 88 \\
\hline $\mathrm{MoS}_{2}$-graphene & $10^{-16}-10^{-13} \mathrm{M}$ & $10^{-17} \mathrm{M}$ & 89 \\
\hline $\mathrm{MoS}_{2}$-graphene-Au NPs-horseradish peroxidase & $5.0 \times 10^{-14}-5.0 \times 10^{-9} \mathrm{M}$ & $2.2 \times 10^{-15} \mathrm{M}$ & 97 \\
\hline $\mathrm{WS}_{2}$-graphene-Au NPs & $0.01-500 \mathrm{pM}$ & $0.0023 \mathrm{pM}$ & 98 \\
\hline $\mathrm{WS}_{2}$-acetylene black & $0.001-100 \mathrm{pM}$ & $0.12 \mathrm{fM}$ & 99 \\
\hline
\end{tabular}


immunosensor based on the Au NP-decorated thionine- $\mathrm{MoS}_{2}$ nanocomposite for the detection of CEA was developed. ${ }^{101}$ Since thionine is an electrochemical indicator, the detection signal was dependent on the peak current of thionine. Apart from electrochemical immunosensors, the electrochemical aptasensors based on TMD composites have been used for the detection of thrombin ${ }^{102}$ and immunoglobulin E. ${ }^{103}$ Aptamers exhibited a highly specific and efficient binding affinity with the target protein. Recently, $\mathrm{Su}$ et al. reported an electrochemical aptasensor based on the Au NP-decorated $\mathrm{MoS}_{2}$ nanosheet for the detection of thrombin, in which the aptamer probe labeled with methylene blue was immobilized on the $\mathrm{Au} \mathrm{NP}-\mathrm{MoS}_{2}$ modified electrode via Au-S bonding. ${ }^{104}$ Upon the addition of thrombin, the distance between methylene blue and the electrode increased, resulting in a decrease of the electrochemical signal. This electrochemical aptasensor could linearly detect thrombin from 0.01 to $10 \mu \mathrm{M}$ with a detection limit of $0.0014 \mathrm{nM}$.

3.2.3 Detection of small molecules. Electrochemical sensing of small molecules, such as $\mathrm{H}_{2} \mathrm{O}_{2}$, glucose, dopamine, uric acid (UA), ascorbic acid (AA), bisphenol, acetaminophen, tryptophan, and chloramphenicol, is another important application of TMD nanosheet-based electrodes in electrochemistry. The first $\mathrm{MoS}_{2}$ nanosheet-based electrochemical sensor was demonstrated by our group recently. ${ }^{105}$ Exfoliated $\mathrm{MoS}_{2}$ nanosheets were electrochemically reduced in $\mathrm{NaCl}$ solution to obtain reduced $\mathrm{MoS}_{2}\left(\mathrm{rMoS}_{2}\right)$ with good conductivity and a fast electron transfer rate in the $\left[\mathrm{Fe}(\mathrm{CN})_{6}\right]^{3-/ 4-}$ and $\left[\mathrm{Ru}\left(\mathrm{NH}_{3}\right)_{6}\right]^{2+/ 3+}$ redox systems. As shown in Fig. 3, the obtained $\mathrm{rMoS}_{2}$ was used for the detection of glucose by immobilizing GOx, and the selective detection of dopamine (DA) in the presence of UA and AA. The reduction current at $-0.33 \mathrm{~V}$, originating from oxygen reduction, decreased with an increased concentration of glucose from 0 to $20 \mathrm{mM}$. In addition, the oxidation peaks of AA, DA, along with UA could be discriminated. The sensor showed a linear range of DA from 1 to $50 \mu \mathrm{M}$ in the presence of AA and UA. Inspired by the excellent properties of $\mathrm{MoS}_{2}$, horseradish peroxidase (HRP) was immobilized on the $\mathrm{MoS}_{2}$-modified electrode. This system exhibited a good electrocatalytic activity toward $\mathrm{H}_{2} \mathrm{O}_{2}$ reduction with a detection limit of $2.6 \times 10^{-7}$ M. ${ }^{106}$ Importantly, the performance of electrochemical sensors based on TMD nanosheets for the detection of small molecules could be further improved through the combination of TMD nanosheets with other nanomaterials, such as $\mathrm{Au}, \mathrm{Ag}, \mathrm{Cu}$, graphene, carbon nanotubes, graphene quantum dots, and polyaniline, since these composites can provide synergistic effects for signal amplification. ${ }^{107,108}$ For example, the Au NP-decorated $\mathrm{MoS}_{2}$ composite could be used for the simultaneous detection of AA,
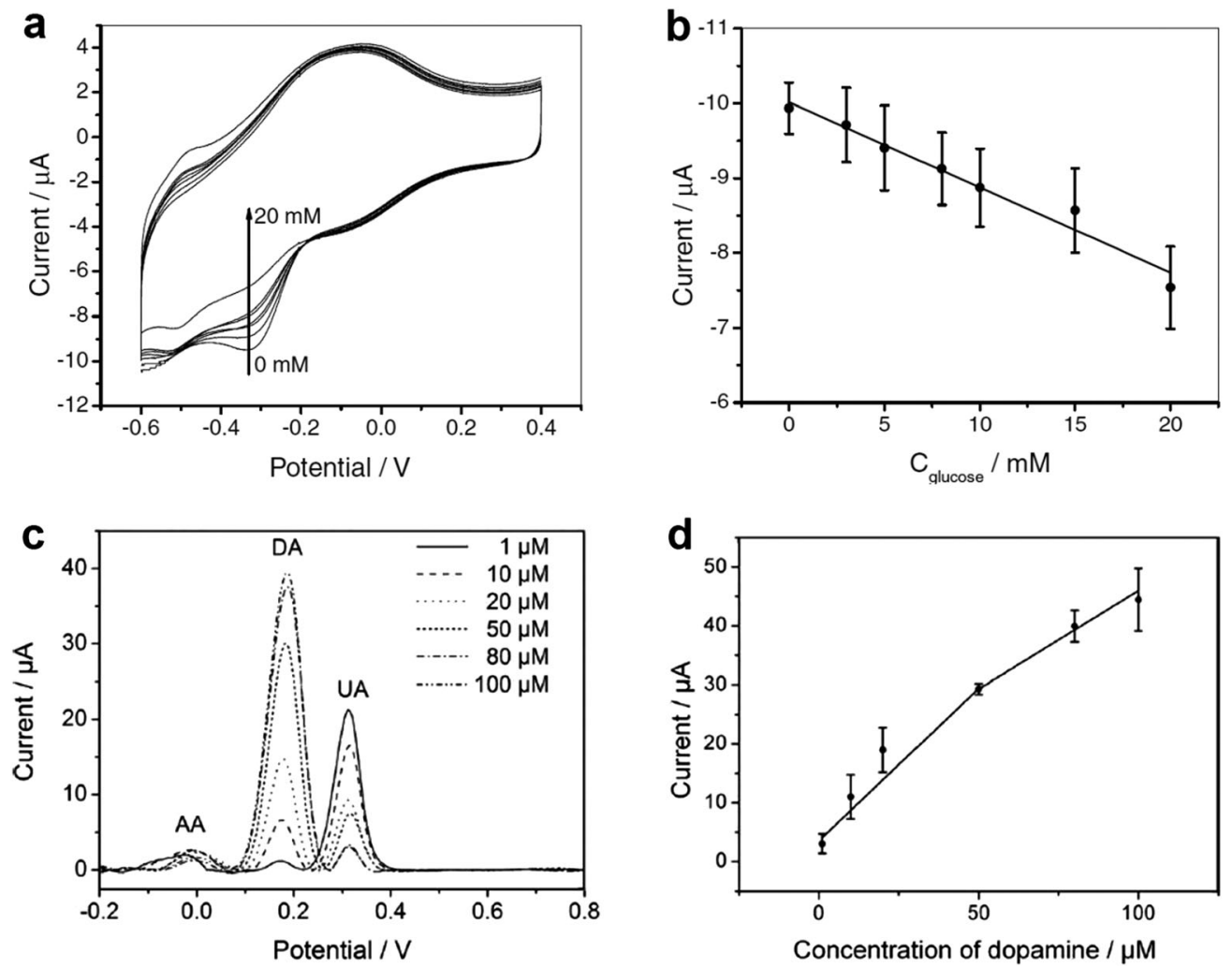

Fig. 3 (a) Cyclic voltammograms of the GCE-APTES-chitosan-rMoS ${ }_{2}$-GOD in air-saturated $0.01 \mathrm{M} \mathrm{PBS}(\mathrm{pH}=7.4$ ) in $0.1 \mathrm{M} \mathrm{KCl}$ solution in the presence of different concentrations of glucose $(0,3,5,8,10,15$ and $20 \mathrm{mM}$ ). (b) The measured calibration curve corresponding to the amperometric response. (c) Differential pulse voltammograms of GCE-APTES-rMoS 2 in $0.1 \mathrm{M}$ PBS ( $\mathrm{pH}=7$ ) solution containing $1 \mathrm{mM} \mathrm{AA}, 0.1 \mathrm{mM}$ UA and DA with different concentrations $(1,10,20,50,80,100 \mu \mathrm{M})$. (d) The oxidation peak current of DA as a function of the concentration of DA. Reproduced with permission from ref. 105. Copyright 2012 Wiley-VCH. 
Table 2 Comparison of the sensing performances of small molecules using different TMD nanosheet-based electrodes

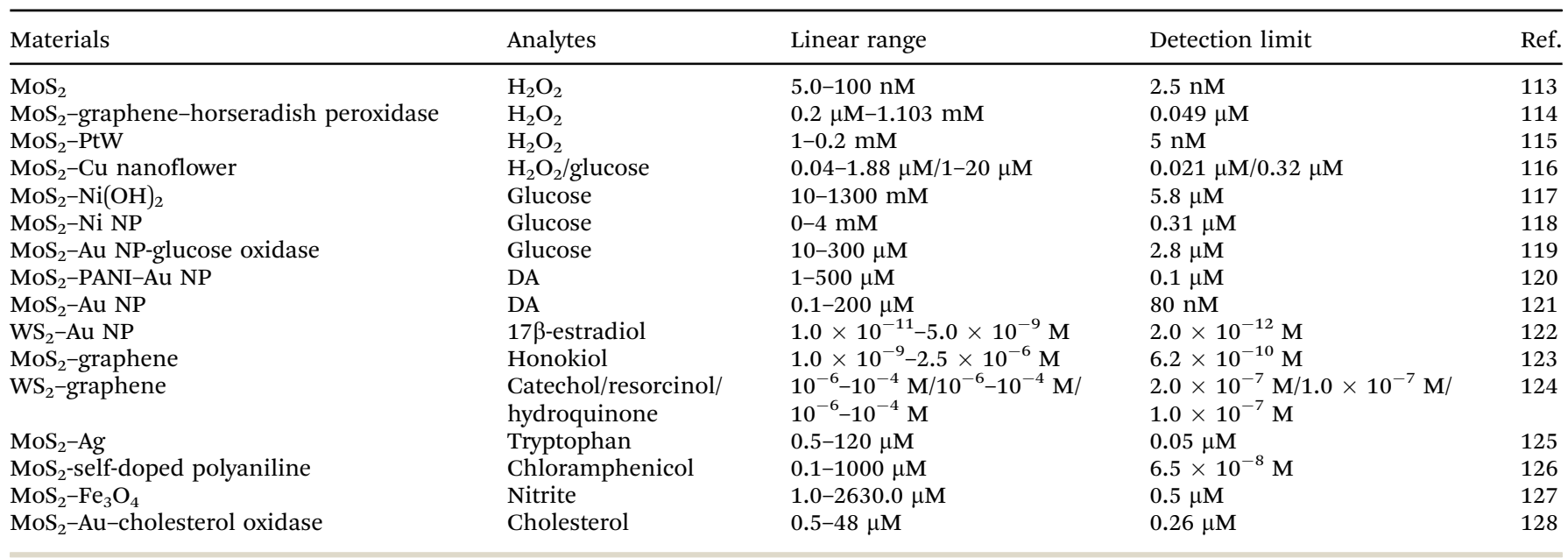

DA and UA. ${ }^{109}$ In addition, it exhibited an electrocatalytic activity for the oxidation of bisphenol A (BPA), with a linear detection range from 0.05 to $100 \mu \mathrm{M}$ and a detection limit of $5.0 \times 10^{-9} \mathrm{M}^{110}$ Besides the Au NP-MoS 2 composite, the $\mathrm{MoS}_{2}-$ graphene composite was also used to construct electrochemical sensors for the detection of acetaminophen. ${ }^{111}$ The good performance was attributed to the synergistic effect between layered $\mathrm{MoS}_{2}$ and graphene. In addition, the self-doped polyanilinedecorated $\mathrm{MoS}_{2}$ exhibited a good electrocatalytic activity for the detection of guanine and adenine compared with the sole polyaniline or $\operatorname{MoS}_{2}{ }^{112}$ In Table 2, the sensing performances of small molecules based on different 2D TMD nanomaterials are summarized.

\subsection{D TMD nanomaterials used for electronic biosensors}

As mentioned in Part 2, the single-layered $\mathrm{MoS}_{2}$ nanosheet has an intrinsic bandgap of 1.8-1.9 eV, making it an ideal candidate for FET sensors. ${ }^{129}$ In a typical FET sensing mode, the adsorption of target molecules on the surface of the semiconducting channel affects the response signal. Recently, Lee et al. successfully fabricated a few-layered $\mathrm{MoS}_{2}$-based bio-FET for DNA detection (Fig. 4a). ${ }^{130}$ The probe DNA molecules were physically adsorbed on the $\mathrm{MoS}_{2}$ channel. When the hybridization between the probe DNA and the target DNA occurred, the signal of the threshold voltage shifted in the negative direction and the drain current increased. This FET sensor could achieve a detection limit of $10 \mathrm{fM}$ and a high dynamic range of $10^{6}$ with a high sensitivity of $17 \mathrm{mV} \mathrm{dec}^{-1}$. In addition, DNA hybridization can also be detected with a detection limit of $\sim$ aM through the FET sensors fabricated using $\mathrm{MoS}_{2} /$ graphene heterostructures. ${ }^{131}$ Moreover, 2D TMD nanosheet-based FET biosensors can also be used for protein detection (Fig. 4b). In a recent study, biotin and SA were chosen as the receptor and target molecules, respectively. ${ }^{132}$ Biotin was used to functionalize the channel of the FET biosensor. When the target molecules were introduced in the FET biosensor, the current of the device decreased due to the negative charge of the SA and the strong bonding between SA and biotin. A high sensitivity of 196 was achieved at a concentration of $100 \mathrm{fM}$.
Furthermore, 2D TMD nanosheet-based FET biosensors can also be used for the detection of other proteins such as PSA. ${ }^{133}$ Moreover, the pH sensor based on $\mathrm{MoS}_{2}$ was also realized, which is 74-fold higher in sensitivity compared to that of the graphenebased FET sensor. ${ }^{132}$

Importantly, TMD nanosheets have been demonstrated to present appealing properties for the fabrication of thin nanopores for DNA translocation with a high sensitivity. Nanopore sequencing has been a promising method in DNA sequencing technologies over the past two decades. ${ }^{134}$ During the sensing process, negatively charged ssDNA or dsDNA is electrophoretically driven to pass through the nanopore, resulting in a temporary blockade with different degrees according to the four DNA nucleotides. ${ }^{135}$ By observing and analyzing the current change, DNA sequencing can be realized. The first use of nanopore sequencing was based on a biological pore. ${ }^{136}$ However, biopores are unstable, often too thick to perform sequencing with a single-base resolution, and a critical conducting environment is required. ${ }^{137,138}$ As a result, the solid-state nanopore with subnanometer thickness becomes more important and attractive. As a typical 2D TMD nanomaterial, the $\mathrm{MoS}_{2}$ nanosheet has been used as a promising material to fabricate nanopores for DNA sequencing. ${ }^{139-141}$ As a typical example, a single- or fewlayered $\mathrm{MoS}_{2}$ nanosheet was suspended on a $20 \mathrm{~nm}$ thick $\mathrm{SiN}_{x}$ membrane which was pre-etched to form a square-shaped opening (Fig. 4c). The $\mathrm{MoS}_{2}$ nanosheet was drilled using a transmission electron microscope to fabricate nanopores ranging between 2 and $20 \mathrm{~nm}$. Compared with graphene, $\mathrm{MoS}_{2}$ has an intrinsic bandgap and shows a higher mechanical stability. ${ }^{142}$ Moreover, unlike graphene ${ }^{143,144}$ and boron nitride, ${ }^{145}$ the $\mathrm{MoS}_{2}$ nanopore showed less interaction with DNA molecules due to the presence of hydrophilic Mo sites in the $\mathrm{MoS}_{2}$ membrane. ${ }^{146}$ As a result, no surface treatments are required to avoid DNA sticking to the surface of the $\mathrm{MoS}_{2}$ nanopore. This $\mathrm{MoS}_{2}$ nanopore technique improved the signal-to-noise ratio and showed a promising application in DNA sequencing at a single-base level. The simulation result was also consistent with the experimental result. ${ }^{146}$ Therefore, TMD nanosheets hold 


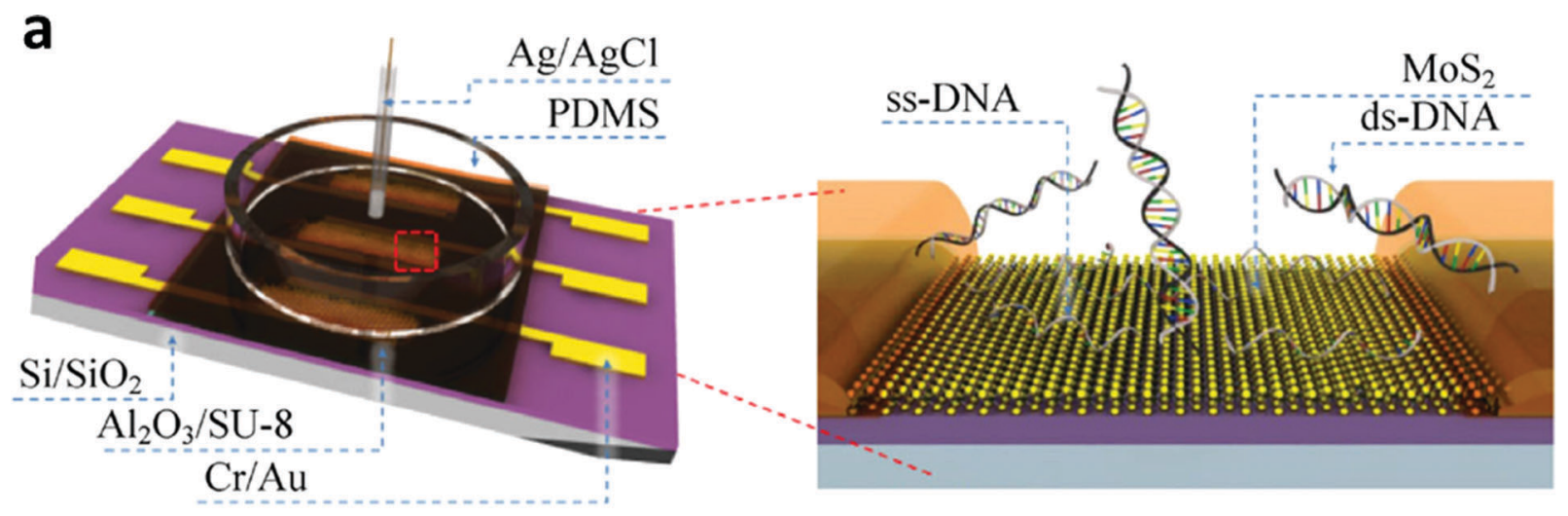

b
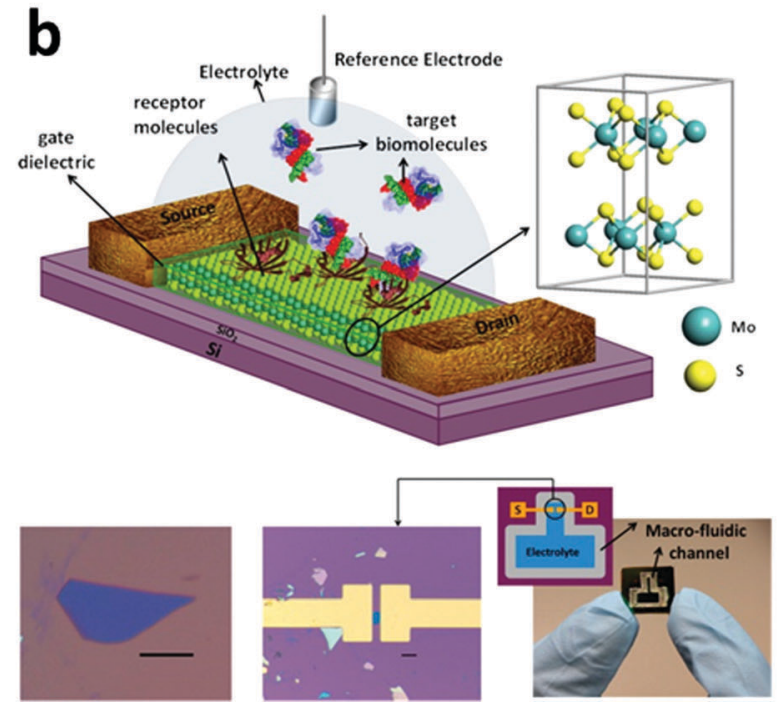

Fig. 4 (a) Schematic illustration of $\mathrm{MoS}_{2}$-based FET. Reproduced with permission from ref. 130. Copyright 2015 Springer. (b) Schematic diagram of the $\mathrm{MoS}_{2}$-based FET biosensor. Reproduced with permission from ref. 132. Copyright 2014 American Chemical Society. (c) Schematic illustration of a MoS 2 nanopore membrane for DNA translocation. Reproduced with permission from ref. 139. Copyright 2014 American Chemical Society.

great promise in the detection of DNA sequencing in the singlebase resolution.

\section{Conclusion and prospects}

Taking advantages of their unique physical and chemical properties, such as a distinctive layered structure, high surface area, and variation of chemical compositions, 2D TMD nanosheets can be used for a great variety of applications, especially the diverse sensing platforms for biological detection. In this mini-review, we introduced the state-of-the-art biosensors based on 2D TMD nanomaterials, including optical, electrochemical, and electronic biosensors for detecting various targets, such as nucleic acid, proteins, and small molecules. We believe that this research field will continuously grow due to the splendid merits of TMD nanomaterials and their synergistic compatibility with other nanomaterials and advanced nanotechnologies.

Although great efforts have been made, there are still lots of challenges in the exploration of 2D TMD nanosheets for biosensing applications. First of all, simple and efficient synthetic methods still need to be established for the preparation of $2 \mathrm{D}$ TMD nanomaterials. In spite of the currently available approaches, a method, which can control the number of layers, size, defects, and morphology of the synthesized 2D TMD nanosheets with low cost and good reproducibility, still needs to be developed since all the aforementioned parameters greatly affect the sensing performance. Second, most studies focused on $\mathrm{MoS}_{2}$ and $\mathrm{WS}_{2}$ for biosensing applications, while other TMD nanosheets, e.g., $\mathrm{MoSe}_{2}, \mathrm{WSe}_{2}$ and $\mathrm{ReSe}_{2}$, have been ignored even though they might show potential to serve as sensing platforms. In the future, more efforts should be devoted to study other kinds of 2D TMD nanosheets. Third, the mechanism of electron transfer between 2D TMD nanosheets and biomaterials should be investigated completely. Better understanding of the interaction between TMD nanosheets and various substances can offer more opportunities to explore sensing applications beyond the current target libraries and to improve the sensitivity beyond the current detection limit. Additionally, the stability, biocompatibility, and long-term toxicity of 2D TMD nanosheets need to be studied in depth. Due to the complex physiological environment, conducting their in vivo biosensing application 
is still a challenge. Combining the advancement of recently developed technologies, we believe that 2D TMD nanosheets hold great promise for single molecule detection. Moreover, inspired by the 2D TMD nanomaterials, many other kinds of 2D nanomaterials have been synthesized, such as graphitic carbon nitride $\left(\mathrm{g}-\mathrm{C}_{3} \mathrm{~N}_{4}\right)$, graphdiyne, $2 \mathrm{D}$ polymer and $2 \mathrm{D}$ metal-organic frameworks (MOFs). ${ }^{147-151}$ Our group has made an attempt to use 2D MOF nanosheets as sensing platforms for the detection of DNA and $\mathrm{H}_{2} \mathrm{O}_{2} \cdot{ }^{149,152}$ Based on the aforementioned description, it is anticipated that beyond the 2D TMD nanomaterials, more 2D nanomaterial-based biosensors will be fabricated in the future, which might have applications in diagnosis, therapy and other biological studies.

\section{Acknowledgements}

This work was supported by MOE under AcRF Tier 2 (ARC 26/ 13, No. MOE2013-T2-1-034; ARC 19/15, No. MOE2014-T2-2-093; MOE2015-T2-2-057) and AcRF Tier 1 (RG5/13), NTU under a Start-Up Grant (M4081296.070.500000) and an iFood Research Grant (M4081458.070.500000), and the Singapore Millennium Foundation in Singapore. It was also supported by the Joint Research Fund for Overseas Chinese, Hong Kong and Macao Scholars (Grant No. 51528201), the National Natural Science Foundation of China (Grant No. GZ213054, 51322202) and the Natural Science Foundation of Jiangsu Province in China (Grant No. BK20130927). H. X. thanks the financial support from the National Natural Science Foundation of China (Grant No. GZ213054, 51322202) and the Natural Science Foundation of Jiangsu Province in China (Grant No. BK20130927).

\section{References}

1 D. Sidransky, Nat. Rev. Cancer, 2002, 2, 210-219.

2 G. Sozzi, D. Conte, M. Leon, R. Ciricione, L. Roz, C. Ratcliffe, E. Roz, N. Cirenei, M. Bellomi, G. Pelosi, M. A. Pierotti and U. Pastorino, J. Clin. Oncol., 2003, 21, 3902-3908.

3 M. Peifer, L. Fernandez-Cuesta, M. L. Sos, J. George, D. Seidel, L. H. Kasper, D. Plenker, F. Leenders, R. Sun, T. Zander, R. Menon, M. Koker, I. Dahmen, C. Muller, V. Di Cerbo, H. U. Schildhaus, J. Altmuller, I. Baessmann, C. Becker, B. de Wilde, J. Vandesompele, D. Bohm, S. Ansen, F. Gabler, I. Wilkening, S. Heynck, J. M. Heuckmann, X. Lu, S. L. Carter, K. Cibulskis, S. Banerji, G. Getz, K. S. Park, D. Rauh, C. Grutter, M. Fischer, L. Pasqualucci, G. Wright, Z. Wainer, P. Russell, I. Petersen, Y. Chen, E. Stoelben, C. Ludwig, P. Schnabel, H. Hoffmann, T. Muley, M. Brockmann, W. Engel-Riedel, L. A. Muscarella, V. M. Fazio, H. Groen, W. Timens, H. Sietsma, E. Thunnissen, E. Smit, D. A. Heideman, P. J. Snijders, F. Cappuzzo, C. Ligorio, S. Damiani, J. Field, S. Solberg, O. T. Brustugun, M. Lund-Iversen, J. Sanger, J. H. Clement, A. Soltermann, H. Moch, W. Weder, B. Solomon, J. C. Soria, P. Validire, B. Besse, E. Brambilla, C. Brambilla, S. Lantuejoul, P. Lorimier, P. M. Schneider, M. Hallek, W. Pao, M. Meyerson, J. Sage, J. Shendure,
R. Schneider, R. Buttner, J. Wolf, P. Nurnberg, S. Perner, L. C. Heukamp, P. K. Brindle, S. Haas and R. K. Thomas, Nat. Genet., 2012, 44, 1104-1110.

4 M. Holzinger, A. Le Goff and S. Cosnier, Front. Chem., 2014, 2, 63.

5 J. Lei and H. Ju, Chem. Soc. Rev., 2012, 41, 2122-2134.

6 X. Bin, E. H. Sargent and S. O. Kelley, Anal. Chem., 2010, 82, 5928-5931.

7 L. Wu, E. H. Xiong, X. Zhang, X. H. Zhang and J. H. Chen, Nano Today, 2014, 9, 197-211.

8 X. Huang, Z. Zeng and H. Zhang, Chem. Soc. Rev., 2013, 42, 1934-1946.

9 M. J. Allen, V. C. Tung and R. B. Kaner, Chem. Rev., 2009, 110, 132-145.

10 D. Chen, L. Tang and J. Li, Chem. Soc. Rev., 2010, 39, 3157-3180. 11 A. Chen and S. Chatterjee, Chem. Soc. Rev., 2013, 42, 5425-5438. 12 A. K. Geim and K. S. Novoselov, Nat. Mater., 2007, 6, 183-191. 13 Y. Liu, X. Dong and P. Chen, Chem. Soc. Rev., 2012, 41, 2283-2307.

14 K. S. Novoselov, A. K. Geim, S. V. Morozov, D. Jiang, Y. Zhang, S. V. Dubonos, I. V. Grigorieva and A. A. Firsov, Science, 2004, 306, 666-669.

15 S. J. He, B. Song, D. Li, C. F. Zhu, W. P. Qi, Y. Q. Wen, L. H. Wang, S. P. Song, H. P. Fang and C. H. Fan, Adv. Funct. Mater., 2010, 20, 453-459.

16 P. J. Huang and J. Liu, Small, 2012, 8, 977-983.

17 J. Li, Y. Huang, D. Wang, B. Song, Z. Li, S. Song, L. Wang, B. Jiang, X. Zhao, J. Yan, R. Liu, D. He and C. Fan, Chem. Commun., 2013, 49, 3125-3127.

18 D. Bitounis, H. Ali-Boucetta, B. H. Hong, D. H. Min and K. Kostarelos, Adv. Mater., 2013, 25, 2258-2268.

19 J. Liu, C. Wang, Y. Jiang, Y. Hu, J. Li, S. Yang, Y. Li, R. Yang, W. Tan and C. Z. Huang, Anal. Chem., 2013, 85, 1424-1430.

20 M. Chhowalla, H. S. Shin, G. Eda, L. J. Li, K. P. Loh and H. Zhang, Nat. Chem., 2013, 5, 263-275.

21 V. Nicolosi, M. Chhowalla, M. G. Kanatzidis, M. S. Strano and J. N. Coleman, Science, 2013, 340, 1226419.

22 Y. Sun, S. Gao and Y. Xie, Chem. Soc. Rev., 2014, 43, 530-546.

23 X. Cao, C. Tan, X. Zhang, W. Zhao and H. Zhang, Adv. Mater., 2016, 28, 6167-6196.

24 C. Tan and H. Zhang, Nat. Commun., 2015, 6, 7873.

25 C. Tan and H. Zhang, J. Am. Chem. Soc., 2015, 137, 12162-12174.

26 J. Zhao, X. Jin, M. Vdovenko, L. Zhang, I. Y. Sakharov and S. Zhao, Chem. Commun., 2015, 51, 11092-11095.

27 C. Tan, Z. Liu, W. Huang and H. Zhang, Chem. Soc. Rev., 2015, 44, 2615-2628.

28 C. Tan and H. Zhang, Chem. Soc. Rev., 2015, 44, 2713-2731.

29 X. Zhang, Z. Lai, C. Tan and H. Zhang, Angew. Chem., Int. Ed., 2016, 55, 8816-8838.

30 Y. H. Lee, X. Q. Zhang, W. J. Zhang, M. T. Chang, C. T. Lin, K. D. Chang, Y. C. Yu, J. T. W. Wang, C. S. Chang, L. J. Li and T. W. Lin, Adv. Mater., 2012, 24, 2320-2325.

31 K. Chang and W. X. Chen, ACS Nano, 2011, 5, 4720-4728.

32 Z. Yin, H. Li, H. Li, L. Jiang, Y. Shi, Y. Sun, G. Lu, Q. Zhang, X. Chen and H. Zhang, ACS Nano, 2012, 6, 74-80. 
33 P. Joensen, R. Frindt and S. R. Morrison, Mater. Res. Bull., 1986, 21, 457-461.

34 K. G. Zhou, N. N. Mao, H. X. Wang, Y. Peng and H. L. Zhang, Angew. Chem., Int. Ed., 2011, 50, 10839-10842.

35 J. N. Coleman, M. Lotya, A. O'Neill, S. D. Bergin, P. J. King, U. Khan, K. Young, A. Gaucher, S. De, R. J. Smith, I. V. Shvets, S. K. Arora, G. Stanton, H. Y. Kim, K. Lee, G. T. Kim, G. S. Duesberg, T. Hallam, J. J. Boland, J. J. Wang, J. F. Donegan, J. C. Grunlan, G. Moriarty, A. Shmeliov, R. J. Nicholls, J. M. Perkins, E. M. Grieveson, K. Theuwissen, D. W. McComb, P. D. Nellist and V. Nicolosi, Science, 2011, 331, 568-571.

36 Z. Y. Zeng, Z. Y. Yin, X. Huang, H. Li, Q. Y. He, G. Lu, F. Boey and H. Zhang, Angew. Chem., Int. Ed., 2011, 50, 11093-11097.

37 A. H. Loo, A. Bonanni, Z. Sofer and M. Pumera, Electrochem. Commun., 2015, 50, 39-42.

38 Q. Lu, Y. Yu, Q. Ma, B. Chen and H. Zhang, Adv. Mater., 2016, 28, 1917-1933.

39 R. Lv, J. A. Robinson, R. E. Schaak, D. Sun, Y. Sun, T. E. Mallouk and M. Terrones, Acc. Chem. Res., 2015, 48, 56-64.

40 Y. H. Kim, K. Y. Kim, Y. R. Choi, Y.-S. Shim, J.-M. Jeon, J.-H. Lee, S. Y. Kim, S. Han and H. W. Jang, J. Mater. Chem. A, 2016, 4, 6070-6076.

41 X. Huang, Z. Zeng, S. Bao, M. Wang, X. Qi, Z. Fan and H. Zhang, Nat. Commun., 2013, 4, 1444.

42 Y. Chen, C. Tan, H. Zhang and L. Wang, Chem. Soc. Rev., 2015, 44, 2681-2701.

43 N. J. Doran, Physica B+C, 1980, 99, 227-237.

44 A. D. Yoffe, Solid State Ionics, 1990, 39, 1-7.

45 Q. H. Wang, K. Kalantar-Zadeh, A. Kis, J. N. Coleman and M. S. Strano, Nat. Nanotechnol., 2012, 7, 699-712.

46 K. F. Mak, C. Lee, J. Hone, J. Shan and T. F. Heinz, Phys. Rev. Lett., 2010, 105, 136805.

47 A. N. Enyashin, L. Yadgarov, L. Houben, I. Popov, M. Weidenbach, R. Tenne, M. Bar-Sadan and G. Seifert, J. Phys. Chem. C, 2011, 115, 24586-24591.

48 D. J. Late, C. S. Rout, D. Chakravarty and S. Ratha, Can. Chem. Trans., 2015, 3, 118-157.

49 M. A. Py and R. R. Haering, Can. J. Phys., 1983, 61, 76-84.

50 C. Tan, W. Zhao, A. Chaturvedi, Z. Fei, Z. Zeng, J. Chen, Y. Huang, P. Ercius, Z. Luo, X. Qi, B. Chen, Z. Lai, B. Li, X. Zhang, J. Yang, Y. Zong, C. Jin, H. Zheng, C. Kloc and H. Zhang, Small, 2016, 12, 1866-1874.

51 H. Wang, Z. Lu, D. Kong, J. Sun, T. M. Hymel and Y. Cui, ACS Nano, 2014, 8, 4940-4947.

52 X. F. Wang, X. Shen, Z. X. Wang, R. C. Yu and L. Q. Chen, ACS Nano, 2014, 8, 11394-11400.

53 F. Wypych and R. Schollhorn, J. Chem. Soc., Chem. Commun., 1992, 1386-1388.

54 H. Li, Z. Yin, Q. He, H. Li, X. Huang, G. Lu, D. W. Fam, A. I. Tok, Q. Zhang and H. Zhang, Small, 2012, 8, 63-67.

55 G. Eda, T. Fujita, H. Yamaguchi, D. Voiry, M. Chen and M. Chhowalla, ACS Nano, 2012, 6, 7311-7317.

56 M. Acerce, D. Voiry and M. Chhowalla, Nat. Nanotechnol., 2015, 10, 313-318.
57 Y. Yang, T. Liu, L. Cheng, G. Song, Z. Liu and M. Chen, ACS Appl. Mater. Interfaces, 2015, 7, 7526-7533.

58 K. Mao, Z. Wu, Y. Chen, X. Zhou, A. Shen and J. Hu, Talanta, 2015, 132, 658-663.

59 C. Zhu, Z. Zeng, H. Li, F. Li, C. Fan and H. Zhang, J. Am. Chem. Soc., 2013, 135, 5998-6001.

60 P. G. Moses, J. J. Mortensen, B. I. Lundqvist and J. K. Norskov, J. Chem. Phys., 2009, 130, 104709.

61 M. Bucci, Nat. Chem. Biol., 2014, 10, 240.

62 X. P. He and H. Tian, Small, 2016, 12, 144-160.

63 D. Chimene, D. L. Alge and A. K. Gaharwar, Adv. Mater., 2015, 27, 7261-7284.

64 G. Yang, C. Zhu, D. Du, J. Zhu and Y. Lin, Nanoscale, 2015, 7, 14217-14231.

65 X. Liu, F. Wang, R. Aizen, O. Yehezkeli and I. Willner, J. Am. Chem. Soc., 2013, 135, 11832-11839.

66 P. M. Sabale, J. T. George and S. G. Srivatsan, Nanoscale, 2014, 6, 10460-10469.

67 Y. Zhang, B. Zheng, C. Zhu, X. Zhang, C. Tan, H. Li, B. Chen, J. Yang, J. Chen, Y. Huang, L. Wang and H. Zhang, Adv. Mater., 2015, 27, 935-939.

68 C. Tan, P. Yu, Y. Hu, J. Chen, Y. Huang, Y. Cai, Z. Luo, B. Li, Q. Lu, L. Wang, Z. Liu and H. Zhang, J. Am. Chem. Soc., 2015, 137, 10430-10436.

69 A. H. Loo, A. Bonanni and M. Pumera, Analyst, 2016, 141, 4654-4658.

70 Y. Huang, Y. Shi, H. Y. Yang and Y. Ai, Nanoscale, 2015, 7, 2245-2249.

71 S. Wang, Y. Zhang, Y. Ning and G. J. Zhang, Analyst, 2015, 140, 434-439.

72 Q. Xi, D. M. Zhou, Y. Y. Kan, J. Ge, Z. K. Wu, R. Q. Yu and J. H. Jiang, Anal. Chem., 2014, 86, 1361-1365.

73 D. H. Bunka and P. G. Stockley, Nat. Rev. Microbiol., 2006, 4, 588-596.

74 J. Ge, E.-C. Ou, R.-Q. Yu and X. Chu, J. Mater. Chem. B, 2014, 2, 625-628.

75 C. H. Lu, H. H. Yang, C. L. Zhu, X. Chen and G. N. Chen, Angew. Chem., Int. Ed., 2009, 48, 4785-4787.

76 Y. Yuan, R. Li and Z. Liu, Anal. Chem., 2014, 86, 3610-3615.

77 R. M. Kong, L. Ding, Z. Wang, J. You and F. Qu, Anal. Bioanal. Chem., 2015, 407, 369-377.

78 X. Yin, J. Cai, H. Feng, Z. Wu, J. Zou and Q. Cai, New J. Chem., 2015, 39, 1892-1898.

79 X. Xiang, J. Shi, F. Huang, M. Zheng, Q. Deng and J. Xu, Biosens. Bioelectron., 2015, 74, 227-232.

80 J. Ge, L. J. Tang, Q. Xi, X. P. Li, R. Q. Yu, J. H. Jiang and X. Chu, Nanoscale, 2014, 6, 6866-6872.

81 X. Liu, J. Ge, X. Wang, Z. Wu, G. Shen and R. Yu, Anal. Methods, 2014, 6, 7212-7217.

82 S. Cai, Q. Han, C. Qi, Z. Lian, X. Jia, R. Yang and C. Wang, Nanoscale, 2016, 8, 3685-3693.

83 T. Lin, L. Zhong, Z. Song, L. Guo, H. Wu, Q. Guo, Y. Chen, F. Fu and G. Chen, Biosens. Bioelectron., 2014, 62, 302-307.

84 T. Lin, L. Zhong, L. Guo, F. Fu and G. Chen, Nanoscale, 2014, 6, 11856-11862. 
85 S. M. Ahmed and H. Gerischer, Electrochim. Acta, 1979, 24, 705-711.

86 K. Saha, S. S. Agasti, C. Kim, X. Li and V. M. Rotello, Chem. Rev., 2012, 112, 2739-2779.

87 J. Ju and W. Chen, Anal. Chem., 2015, 87, 1903-1910.

88 T. Yang, L. Meng, H. Chen, S. Luo, W. Li and K. Jiao, Adv. Mater. Interfaces, 2016, 3, 1500700.

89 Y. Chu, B. Cai, Y. Ma, M. Zhao, Z. Ye and J. Huang, RSC Adv., 2016, 6, 22673-22678.

90 Q. Wang, Y. Zhang, W. Ye and C. Wang, J. Solid State Electrochem., 2015, 20, 133-142.

91 Z. Xing, X. Yang, A. M. Asiri and X. Sun, ACS Appl. Mater. Interfaces, 2016, 8, 14521-14526.

92 A. H. Loo, A. Bonanni, A. Ambrosi and M. Pumera, Nanoscale, 2014, 6, 11971-11975.

93 T. Wang, R. Zhu, J. Zhuo, Z. Zhu, Y. Shao and M. Li, Anal. Chem., 2014, 86, 12064-12069.

94 X. Wang, F. Nan, J. Zhao, T. Yang, T. Ge and K. Jiao, Biosens. Bioelectron., 2015, 64, 386-391.

95 K. J. Huang, Y. J. Liu, H. B. Wang, Y. Y. Wang and Y. M. Liu, Biosens. Bioelectron., 2014, 55, 195-202.

96 T. Yang, M. Chen, Q. Kong, X. Luo and K. Jiao, Biosens. Bioelectron., 2016, DOI: 10.1016/j.bios.2016.03.025.

97 X. Cao, Microchim. Acta, 2014, 181, 1133-1141.

98 K.-J. Huang, Y.-J. Liu, H.-B. Wang, T. Gan, Y.-M. Liu and L.-L. Wang, Sens. Actuators, B, 2014, 191, 828-836.

99 H. L. Shuai, K. J. Huang and Y. X. Chen, J. Mater. Chem. B, 2016, 4, 1186-1196.

100 X. Wang, C. Chu, L. Shen, W. Deng, M. Yan, S. Ge, J. Yu and X. Song, Sens. Actuators, B, 2015, 206, 30-36.

101 S. Su, M. Zou, H. Zhao, C. Yuan, Y. Xu, C. Zhang, L. Wang, C. Fan and L. Wang, Nanoscale, 2015, 7, 19129-19135.

102 P. Jing, H. Yi, S. Xue, Y. Chai, R. Yuan and W. Xu, Anal. Chim. Acta, 2015, 853, 234-241.

103 K.-J. Huang, Y.-J. Liu, J.-T. Cao and H.-B. Wang, RSC Adv., 2014, 4, 36742-36748.

104 S. Su, H. Sun, W. Cao, J. Chao, H. Peng, X. Zuo, L. Yuwen, C. Fan and L. Wang, ACS Appl. Mater. Interfaces, 2016, 8, 6826-6833.

105 S. X. Wu, Z. Y. Zeng, Q. Y. He, Z. J. Wang, S. J. Wang, Y. P. Du, Z. Y. Yin, X. P. Sun, W. Chen and H. Zhang, Small, 2012, 8, 2264-2270.

106 G. X. Wang, W. J. Bao, J. Wang, Q. Q. Lu and X. H. Xia, Electrochem. Commun., 2013, 35, 146-148.

107 S. Su, J. Chao, D. Pan, L. H. Wang and C. H. Fan, Electroanalysis, 2015, 27, 1062-1072.

108 P. Bollella, G. Fusco, C. Tortolini, G. Sanzo, G. Favero, L. Gorton and R. Antiochia, Biosens. Bioelectron., 2016, DOI: 10.1016/j.bios.2016.03.068.

109 H. F. Sun, J. Chao, X. L. Zuo, S. Su, X. F. Liu, L. H. Yuwen, C. H. Fan and L. H. Wang, RSC Adv., 2014, 4, 27625-27629.

110 K. J. Huang, Y. J. Liu, Y. M. Liu and L. L. Wang, J. Hazard. Mater., 2014, 276, 207-215.

111 K.-J. Huang, L. Wang, J. Li and Y.-M. Liu, Sens. Actuators, B, 2013, 178, 671-677.
112 T. Yang, R. Yang, H. Chen, F. Nan, T. Ge and K. Jiao, ACS Appl. Mater. Interfaces, 2015, 7, 2867-2872.

113 T. Wang, H. Zhu, J. Zhuo, Z. Zhu, P. Papakonstantinou, G. Lubarsky, J. Lin and M. Li, Anal. Chem., 2013, 85, 10289-10295.

114 H. Song, Y. Ni and S. Kokot, Biosens. Bioelectron., 2014, 56, 137-143.

115 L. Zhu, Y. Zhang, P. Xu, W. Wen, X. Li and J. Xu, Biosens. Bioelectron., 2016, 80, 601-606.

116 X. Lin, Y. Ni and S. Kokot, Biosens. Bioelectron., 2016, 79, 685-692.

117 S. S. Ji, Z. Yang, C. Zhang, Y. E. Miao, W. W. Tjiu, J. S. Pan and T. X. Liu, Microchim. Acta, 2013, 180, 1127-1134.

118 J. W. Huang, Y. Q. He, J. Jin, Y. R. Li, Z. P. Dong and R. Li, Electrochim. Acta, 2014, 136, 41-46.

119 S. Su, H. F. Sun, F. Xu, L. H. Yuwen, C. H. Fan and L. H. Wang, Microchim. Acta, 2014, 181, 1497-1503.

120 K. J. Huang, J. Z. Zhang, Y. J. Liu and L. L. Wang, Sens. Actuators, B, 2014, 194, 303-310.

121 S. Su, H. F. Sun, F. Xu, L. H. Yuwen and L. H. Wang, Electroanalysis, 2013, 25, 2523-2529.

122 K. J. Huang, Y. J. Liu, J. Z. Zhang and Y. M. Liu, Anal. Methods, 2014, 6, 8011-8017.

123 X. J. Zhao, X. H. Xia, S. J. Yu and C. M. Wang, Anal. Methods, 2014, 6, 9375-9382.

124 K. J. Huang, L. Wang, Y. J. Liu, T. Gan, Y. M. Liu, L. L. Wang and Y. Fan, Electrochim. Acta, 2013, 107, 379-387.

125 X. Xia, Z. Zheng, Y. Zhang, X. Zhao and C. Wang, Sens. Actuators, B, 2014, 192, 42-50.

126 R. Yang, J. Zhao, M. Chen, T. Yang, S. Luo and K. Jiao, Talanta, 2015, 131, 619-623.

127 Y. Zhang, P. Chen, F. Wen, B. Yuan and H. Wang, J. Electroanal. Chem., 2016, 761, 14-20.

128 X. Lin, Y. Ni and S. Kokot, Sens. Actuators, B, 2016, 233, 100-106.

129 B. Radisavljevic, A. Radenovic, J. Brivio, V. Giacometti and A. Kis, Nat. Nanotechnol., 2011, 6, 147-150.

130 D. W. Lee, J. Lee, I. Y. Sohn, B. Y. Kim, Y. M. Son, H. Bark, J. Jung, M. Choi, T. H. Kim, C. Lee and N. E. Lee, Nano Res., 2015, 8, 2340-2350.

131 P. T. Loan, W. Zhang, C. T. Lin, K. H. Wei, L. J. Li and C. H. Chen, Adv. Mater., 2014, 26, 4838-4844.

132 D. Sarkar, W. Liu, X. Xie, A. C. Anselmo, S. Mitragotri and K. Banerjee, ACS Nano, 2014, 8, 3992-4003.

133 L. Wang, Y. Wang, J. I. Wong, T. Palacios, J. Kong and H. Y. Yang, Small, 2014, 10, 1101-1105.

134 L. J. Steinbock and A. Radenovic, Nanotechnology, 2015, 26, 074003.

135 M. Fyta, J. Phys.: Condens. Matter, 2015, 27, 273101.

136 J. J. Kasianowicz, E. Brandin, D. Branton and D. W. Deamer, Proc. Natl. Acad. Sci. U. S. A., 1996, 93, 13770-13773.

137 D. Branton, D. W. Deamer, A. Marziali, H. Bayley, S. A. Benner, T. Butler, M. Di Ventra, S. Garaj, A. Hibbs, X. Huang, S. B. Jovanovich, P. S. Krstic, S. Lindsay, X. S. Ling, C. H. Mastrangelo, A. Meller, J. S. Oliver, Y. V. Pershin, J. M. Ramsey, R. Riehn, G. V. Soni, V. Tabard-Cossa, 
M. Wanunu, M. Wiggin and J. A. Schloss, Nat. Biotechnol., 2008, 26, 1146-1153.

138 S. M. Iqbal, D. Akin and R. Bashir, Nat. Nanotechnol., 2007, 2, 243-248.

139 K. Liu, J. Feng, A. Kis and A. Radenovic, ACS Nano, 2014, 8, 2504-2511.

140 J. Feng, K. Liu, M. Graf, M. Lihter, R. D. Bulushev, D. Dumcenco, D. T. Alexander, D. Krasnozhon, T. Vuletic, A. Kis and A. Radenovic, Nano Lett., 2015, 15, 3431-3438.

141 J. Feng, K. Liu, R. D. Bulushev, S. Khlybov, D. Dumcenco, A. Kis and A. Radenovic, Nat. Nanotechnol., 2015, 10, 1070-1076.

142 H. Arjmandi-Tash, L. A. Belyaeva and G. F. Schneider, Chem. Soc. Rev., 2016, 45, 476-493.

143 C. Sathe, X. Q. Zou, J. P. Leburton and K. Schulten, ACS Nano, 2011, 5, 8842-8851.

144 Z. S. Siwy and M. Davenport, Nat. Nanotechnol., 2010, 5, 697-698.
145 Z. Zhou, Y. Hu, H. Wang, Z. Xu, W. Wang, X. Bai, X. Shan and X. Lu, Sci. Rep., 2013, 3, 3287.

146 A. B. Farimani, K. Min and N. R. Aluru, ACS Nano, 2014, 8, 7914-7922.

147 C. Wang, P. Yu, S. Guo, L. Mao, H. Liu and Y. Li, Chem. Commun., 2016, 52, 5629-5632.

148 T. Rodenas, I. Luz, G. Prieto, B. Seoane, H. Miro, A. Corma, F. Kapteijn, F. X. Llabres i Xamena and J. Gascon, Nat. Mater., 2015, 14, 48-55.

149 M. Zhao, Y. Wang, Q. Ma, Y. Huang, X. Zhang, J. Ping, Z. Zhang, Q. Lu, Y. Yu, H. Xu, Y. Zhao and H. Zhang, Adv. Mater., 2015, 27, 7372-7378.

150 T. Y. Ma, Y. Tang, S. Dai and S. Z. Qiao, Small, 2014, 10, 2382-2389.

151 P. Kissel, D. J. Murray, W. J. Wulftange, V. J. Catalano and B. T. King, Nat. Chem., 2014, 6, 774-778.

152 Y. Wang, M. Zhao, J. Ping, B. Chen, X. Cao, Y. Huang, C. Tan, Q. Ma, S. Wu, Y. Yu, Q. Lu, J. Chen, W. Zhao, Y. Ying and H. Zhang, Adv. Mater., 2016, 28, 4149-4155. 